\title{
DRYING PERFORMANCE OF ROTATING AND SOLAR TUNNEL DRYER FOR PRODUCTION OF QUALITY DRIED FISH
}

\author{
S. Sultana, Shikha, M. N. Islam and M. Kamal* \\ Department of Fisheries Technology, Bangladesh Agricultural University \\ Mymensingh-2202, Bangladesh
}

\begin{abstract}
Studies were conducted to evaluate the drying performance of rotating and solar tunnel dryer for the production of high quality dried fish products. Three marine fish species : Silver jew fish (Johnius argentatus), Bombay duck (Harpodon nehereus) and Ribbon fish (Trichiurus haumela) were used for drying in a rotating dryer and solar tunnel dryer. Temperature and relative humidity were measured at time interval during the whole drying period. During 20 hours of drying in rotating dryer, temperature and humidity varied from $15-20^{\circ} \mathrm{C}$ and 45 to $72 \%$, respectively. On the other hand, air temperature outside the tunnel dryer varied from 28 to $32.83^{\circ} \mathrm{C}$. Temperature inside the tunnel dryer varied from $31.33^{\circ} \mathrm{C}$ at $3.00 \mathrm{pm}$ to $47.78^{\circ} \mathrm{C}$ at $12.00 \mathrm{pm}$. Humidity outside the tunnel dryer ranged from 58.83 to $74 \%$ and inside from $33.83 \%$ to $68 \%$ showing an inverse relationship between temperature and humidity. Moisture content of the fresh Ribbon fish, Silver Jew fish and Bombay duck was in the range of $78.7 \%$ to $85.47 \%$ with highest value was found in Bombay duck and lowest value in Ribbon fish. After 31 hours of drying in solar tunnel dryer, moisture content decreased in the range of 14.05 to $16.19 \%$. whereas, after 20 hours of drying in rotating dryer final moisture content reached in the range of 16.36 to $19.1 \%$. The present study indicated that drying performance of rotating dryer with low humidity was faster than that of solar tunnel dryer producing quality dried products.
\end{abstract}

Key words : Drying performances, Rotating dryer, Solar tunnel dryer

\section{INTRODUCTION}

Drying of fish is carried out by traditional sun drying method in Bangladesh. It is one of the most popular, primitive, low-cost and widely used fish preservation method. About $20 \%$ of the marine artisanal catch is sun dried and consumed in the internal domestic market (Coulter and Disney, 1987). The physical and organoleptic qualities of most of the traditional sun dried products available in the market are not satisfactory for human consumption (Reza et al., 2005; Hasan, 2006). There are frequent complaints from the consumers about the quality of the traditionally produced sun dried fish products and the major problems associated with the traditional sun drying of fish are infestation by

*Corresponding E-mail :- klab07@hotmail.com 
the fly and insect larvae during drying and storage, contamination with sand, filth and dust, and spoilage. The quantitative loss through spoilage and insect attack on fish being dried has been estimated as 10-35\% in the marine areas (Doe et al., 1977; Ahmed et al., 1978). In tropical climates, under humid conditions, heavy infestation of unsalted dried fish by blow flies may cause up to $30 \%$ loss of the product (Wood, 1981).

To avoid the infestation due to insect and larvae attacks and for safe storage of commercial dried fish, the producers apply various types of insecticides including DDT, Nagos and Rubral etc. in fish during drying and storage. These contaminated products create environmental and health hazards. In a previous study, a Hohenheim type solar tunnel dryer constructed with locally available material was found very suitable for drying of Silver Jew fish at temperature of 35 to $52^{\circ} \mathrm{C}$ for 5 days without showing any infestation, oxidative rancidity, spoilage and contamination (Bala and Hossain, 1998; Bala and Mandal, 2001; Reza, 2002; Reza et al., 2006; Hasan, 2006). However, solar dryer is not suitable for drying during rainy season when large quantities of fishes are caught in the coastal areas of Bangladesh. There is a demand from the marginal processors for developing a dryer which can be used without sun round the year. The rotating dryer is a suitable technology widely used in Japan for producing high quality dried fish in all weather conditions. The present study was undertaken to evaluate the drying performances of rotating and solar tunnel dryer.

\section{MATERIALS AND METHODS}

\section{Rotating dryer}

Rotating dryer was developed and constructed using locally available materials. The dryer essentially consists of Thai aluminium structure bearing hooks and stainless steel ring. The aluminium structure is supported by S.S. pipe and bearing. Nut bolts are used to join interconnected parts of the dryer. The dryer is operated by $0.75 \mathrm{HP}$ motor having speed regulator. In the present study the rotating dryer was operated at speed of 90 rotations per minute (RPM). The whole system is placed vertically on raised $2 " \times 2$ " angel platform. Hooks and stainless steel structure are used to hang large size fishes and round shaped plastic net was used as additional platform for drying of small fishes (Plate 1 and 2). When the system is on, the dryer rotates and ambient air passes over fishes, which enhance the drying process. The rotating dryer was constructed using locally available materials. About $40 \mathrm{~kg}$ of fishes like jewfish, Bombay duck and ribbon fish can be dried at a time in a rotating dryer. The dryer was placed inside the laboratory of the Department of Fisheries Technology, BAU, Mymensingh.

\section{Solar tunnel dryer}

A Hohenheim type solar dryer was used for drying marine fish products which was constructed using locally available materials and the size of the dryer was $20 \mathrm{~m} \times 2 \mathrm{~m}$ with $20 \mathrm{~m}^{2}$ drying area. The solar tunnel dryer consists of a flat plate air-heating collector, a tunnel-drying unit and four small fans to provide the required airflow over the product to be dried. Both the collector and the drying unit are covered with transparent polythene 
sheet. Black paint is used as heat absorber in the collector. The products to be dried are placed in a thin layer on a bamboo made mat in the tunnel dryer. The whole system is placed horizontally on a raised platform. The air is provided by four DC fans operated by two photovoltaic modules as the air is passed over the products. The black painted collector absorbs heat through transparent polythene from sunlight. The air from the fans blows over the collector and then heated air passes over the products. Solar radiation also passes through the transparent cover of the dryer and heats the products in the dryer (Plate 3). This enhances the drying rate and the temperature in the dryer in the ranges of $35^{\circ} \mathrm{C}$ to $55^{\circ} \mathrm{C}$. The solar dryer was placed in the vicinity of the Faculty of Fisheries, Bangladesh Agricultural University (BAU) in an open air where the dryer got direct sunlight throughout the day.

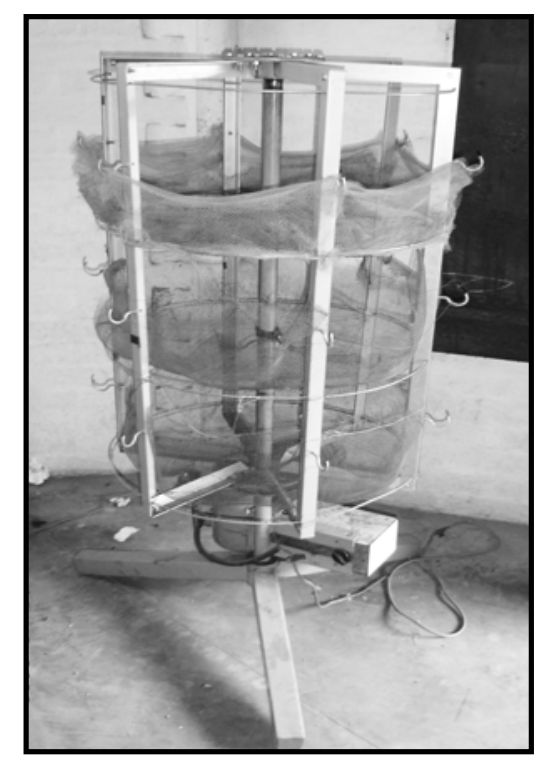

Plate No. 1. Rotating dryer without fish

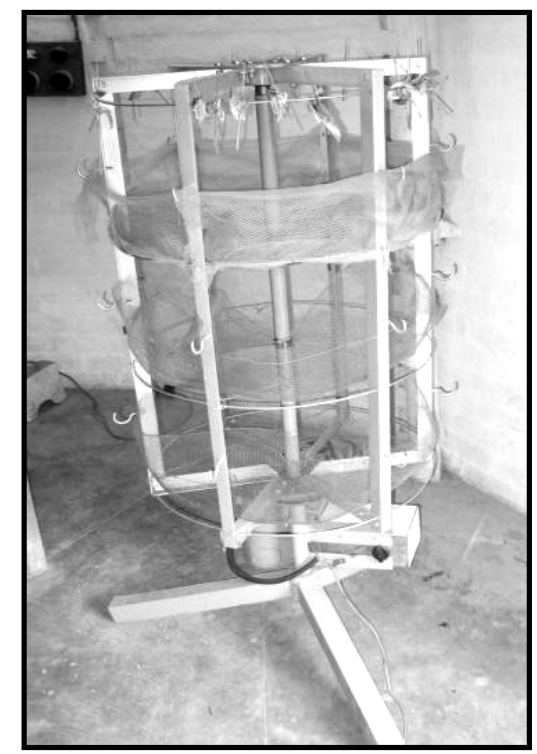

Plate No. 2. Rotating dryer with fish

\section{Processing method}

A flow chart of the processing and drying in rotating and solar dried products is given in Fig. 1.

\section{Drying performances of rotating and solar tunnel dryer Sample collection}

Three fresh marine fish samples viz. silver jew fish (Johnius argentatus), Bombay duck (Harpodon nehereus) and Ribbon fish (Trichiurus haumela) were collected from a local fish market of Chittagong in October 2008 and transported to the laboratory of the Department of Fisheries Technology, Bangladesh Agricultural University, Mymensingh in an insulated box in ice $(1: 1)$. The samples were processed and dried in solar dryer and rotating dryer according to the flow diagram given in Fig. 1. 


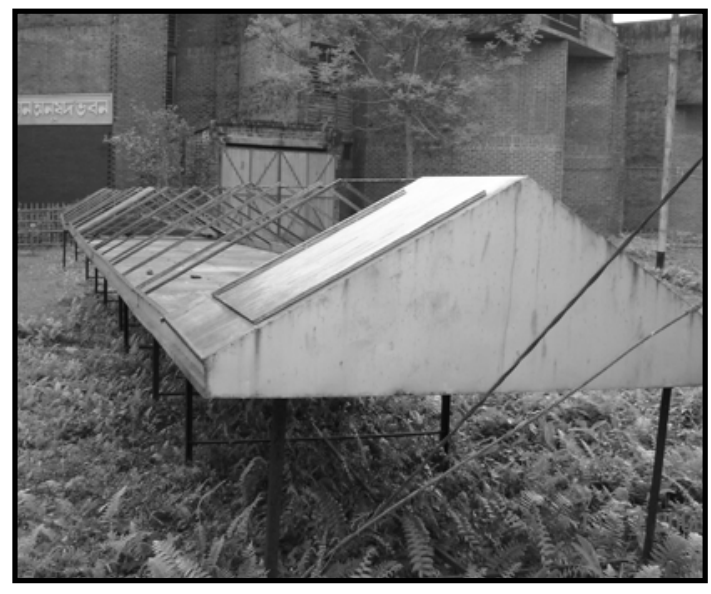

Plate No. 3. Solar tunnel dryer used for drying

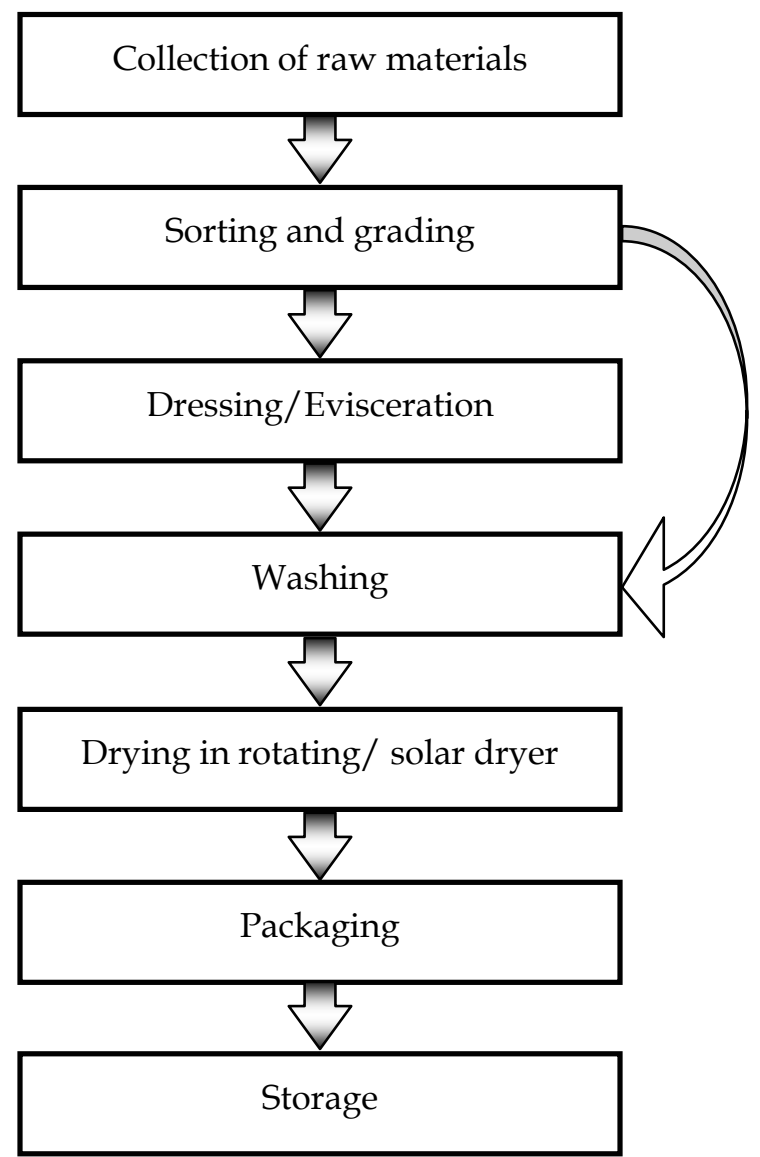

Fig. 1. Processing and drying steps of solar tunnel and rotating dryer 


\section{Determination of moisture content}

Moisture content of the products dried in solar dryer and rotating dryer was determined according to AOAC (1980). Briefly, placed accurately weighed known amount of ground sample $(2-5 \mathrm{~g})$ in a pre-weighed porcelain crucible in a thermostat controlled oven (Gallenkamp, HOTBOX, Model OVB-306) at $105^{\circ} \mathrm{C}$ for about $24 \mathrm{hrs}$ until constant weight was obtained. The loss of moisture for each sample was calculated as percent moisture.

\section{Temperature and humidity measurement}

Air temperature inside and outside of the solar tunnel and rotating dryer at various locations of $5 \mathrm{~m}$ distance was measured by using thermometers. The relative humidity inside and outside of both dryers was also measured at various locations using relative humidity meter recorded by a data logger.

Temperature and humidity data of solar tunnel dryer during drying of fish samples were collected every one hour interval. On the other hand, the data of moisture reduction of the samples during drying in rotating and solar tunnel dryers was collected at every 2 hours intervals.

The drying process in solar tunnel dryer under direct sunlight started at $9.00 \mathrm{am}$ and continued up to $3.00 \mathrm{pm}$. In rotating dryer the samples dried from 9.45 am to $7.45 \mathrm{pm}$ every day. Then the samples of both dryers were collected and kept in air tight condition in polyethylene bags at refrigerator. Next morning samples were again dried until moisture content reached below $16 \%$. Samples of each of three fish species were collected every one hour interval from solar tunnel dryer and every two hours interval from rotating dryer to measure the moisture content.

\section{RESULTS AND DISCUSSION}

The temperature and relative humidity in both inside and outside the solar tunnel dryer were recorded during the drying period, whereas for rotating dryer only atmospheric temperature and relative humidity were recorded.

Temperature and humidity changing pattern during drying in rotating dryer has been presented in Fig. 2. Temperature varied between $15-20^{\circ} \mathrm{C}$ with the minimum recorded in the morning and maximum in the afternoon. Humidity varied from $45-72 \%$ with highest value recorded in the morning and lowest in the afternoon. A close relationship between temperature and humidity was observed where humidity was high at low temperature and vice-versa.

Fig 3 shows the changes in the moisture content during drying in rotating dryer. As shown in the figure the moisture reduction patterns of the three fish samples are more or less similar. In first 2 hours of drying moisture reduction was very rapid because in this phase (first phase of drying named constant drying rate) moisture is removed directly 
from the fish surface and the rate of reduction depended on the attributes of air surrounding the fish i.e. air velocity, relative humidity, temperature etc. And the next 310 hours of drying the trend of moisture loss gradually slowed down. This is because of the initiation of second phase of drying i.e. falling rate of drying. In this phase, moisture from the deeper portion of muscle are brought to the surface and then evaporated. As the amount of moisture in the fish falls, the rate of movement of moisture to the surface is reduced and the drying rate becomes slower. Finally all the fish samples reached moisture content of less than $20 \%$ within 17 to 20 hours of drying. Compared to other two species, silver jew fish dried and moisture content reached to $16.36 \%$ within 17 hours of drying. In the present study silver jew fish was splitted before drying and have larger surface area accelerated drying rate.

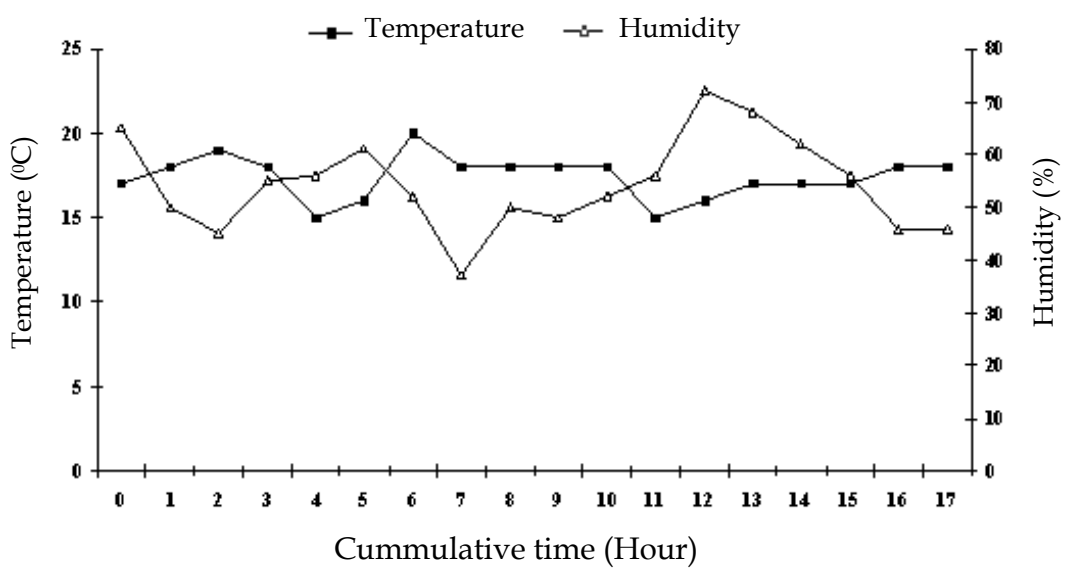

Fig. 2. Temperature and humidity changing pattern with cummulative time interval during drying in rotating dryer

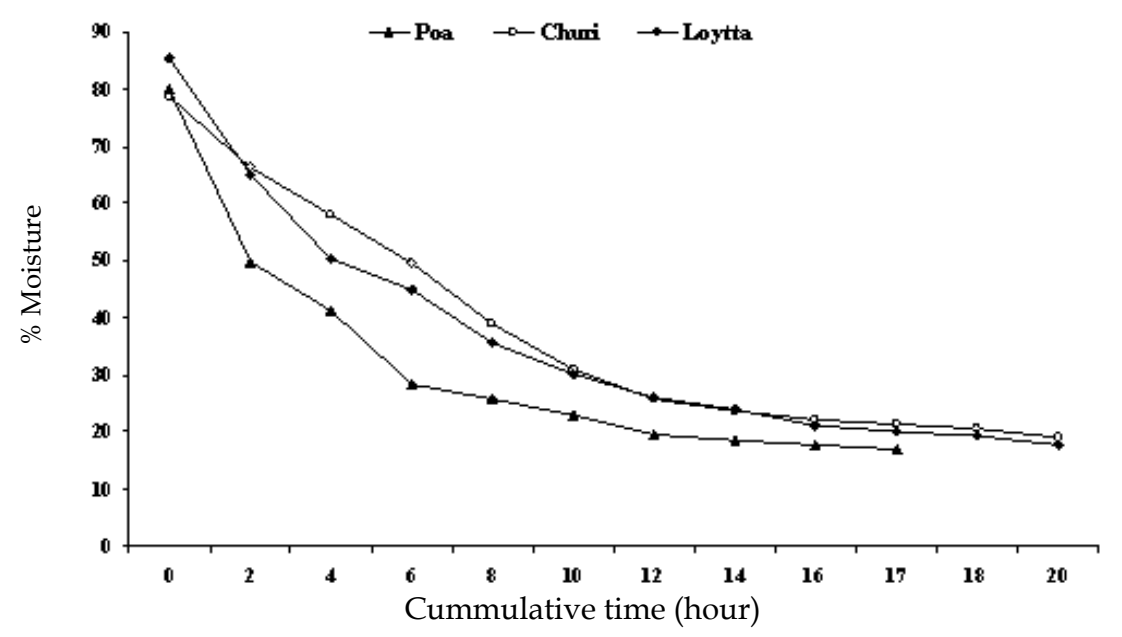

Fig. 3. Changing in moisture content with cummulative time interval during drying in rotating dryer 
Changing pattern of temperature and relative humidity outside and inside the tunnel of solar dryer are shown in Fig. 4 and 5, respectively. Outside the tunnel temperature varied from 28 to $32.83^{\circ} \mathrm{C}$ and humidity varied from 58.83 to $74 \%$. But inside the tunnel, fluctuation of temperature was high with minimum of $31.33^{\circ} \mathrm{C}$ and maximum of $47.78^{\circ} \mathrm{C}$. Relative humidity was in the range of 33.83 to $68 \%$, with higher in the afternoon and lower in the morning. Here, as in rotating dryer it was found the opposite relationship between temperature and humidity. The relative humidity inside the tunnel was lower compared to outside the tunnel which accelerated the faster drying rate by absorbing greater amount of water from the fish body.

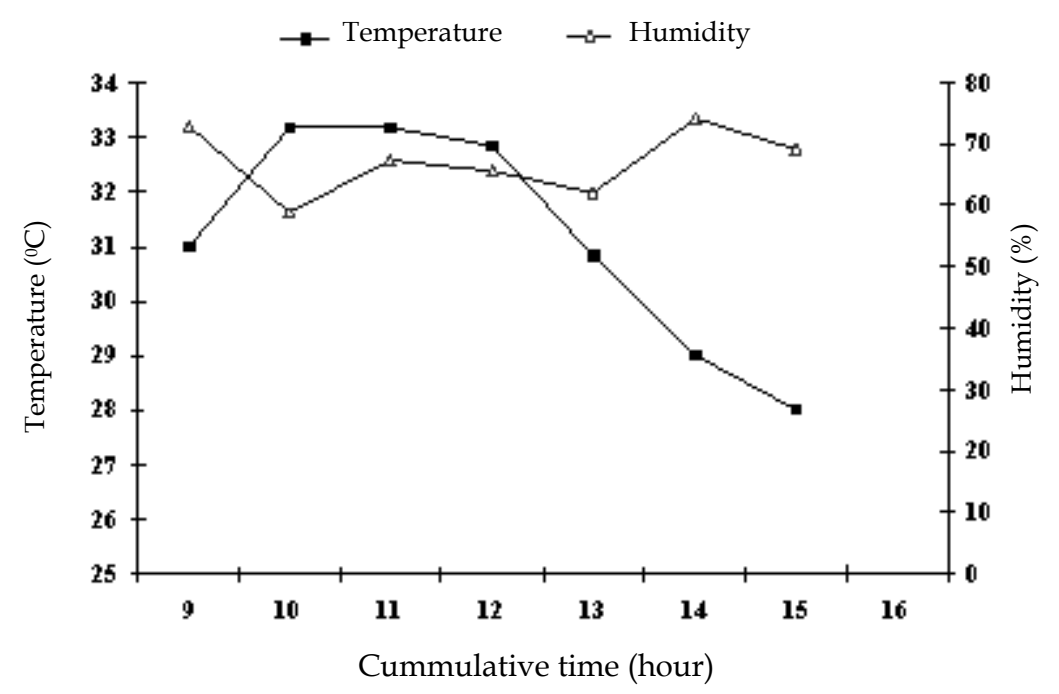

Fig. 4. Relationship between atmospheric temperature and humidity inside tunnel with time during drying in solar tunnel dryer

Changes in moisture content with time interval during drying in solar tunnel dryer has been presented in Fig. 6. From this figure it reveals that the moisture content of three fish samples declined very rapidly during the first 2 hours of drying; the pattern which is more or less similar to that of rotating dryer. Then the moisture content declined very slowly. The temperature inside the tunnel increased gradually until $3.00 \mathrm{pm}$ and remained higher compared to the outside temperature and this higher temperature obviously accelerated drying performance. High temperature and low humidity inside the tunnel accelerated faster drying compared to open air drying. Compared to rotating dryer it takes longer drying period of 26 to 31 hours and at the end of drying moisture content reached to below $20 \%$ in all the samples. But the moisture content of silver jew fish required more than 30 hours drying time compared to other two species. The reason of longer drying period might be associate with the nature of constituent of the fish; the fat content of silver jew fish which was higher than other two species. Silver jew fish having high fat content severely prevent the drying process and it takes longer time for drying than other two species. This indicates that the water content decreases linearly with fat content. Thickness of skin and muscle may be another reason, which prevents the 
quick evaporation of moisture from fish body. It is because as the thicker the fish, the further the water in the middle layers has to travel to reach the surface.

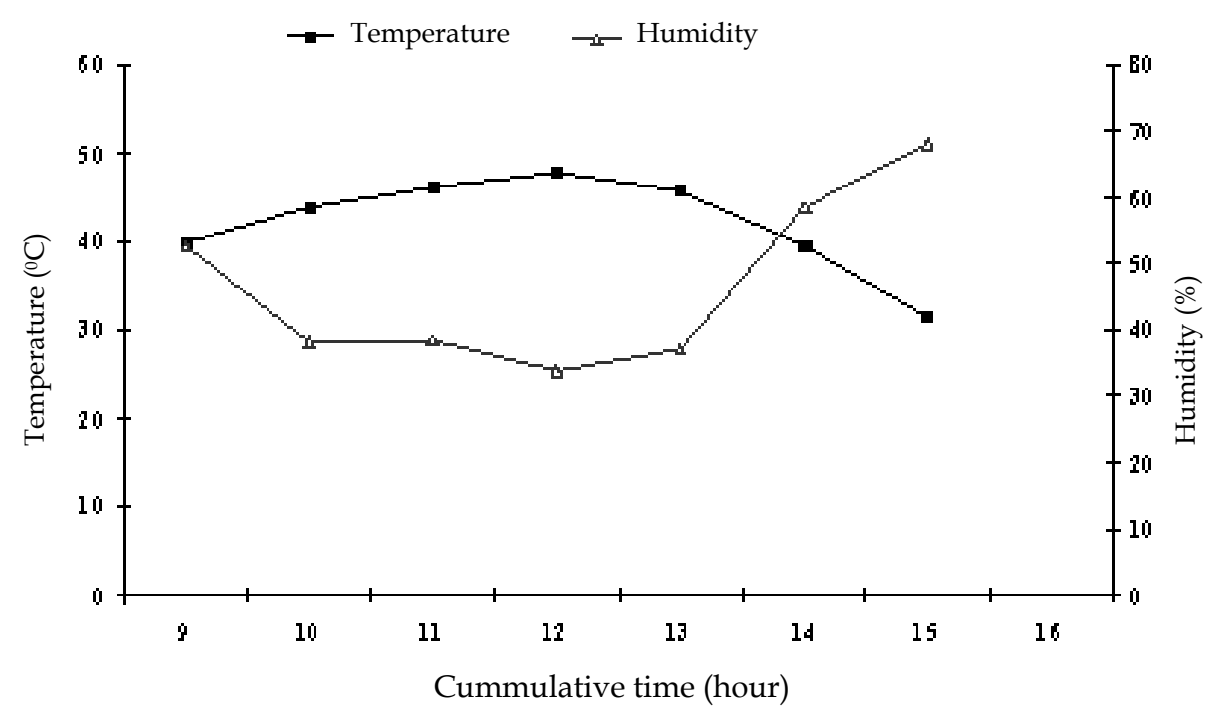

Fig. 5. Relationship between atmospheric temperature and humidity inside tunnel with time during drying in solar tunnel dryer

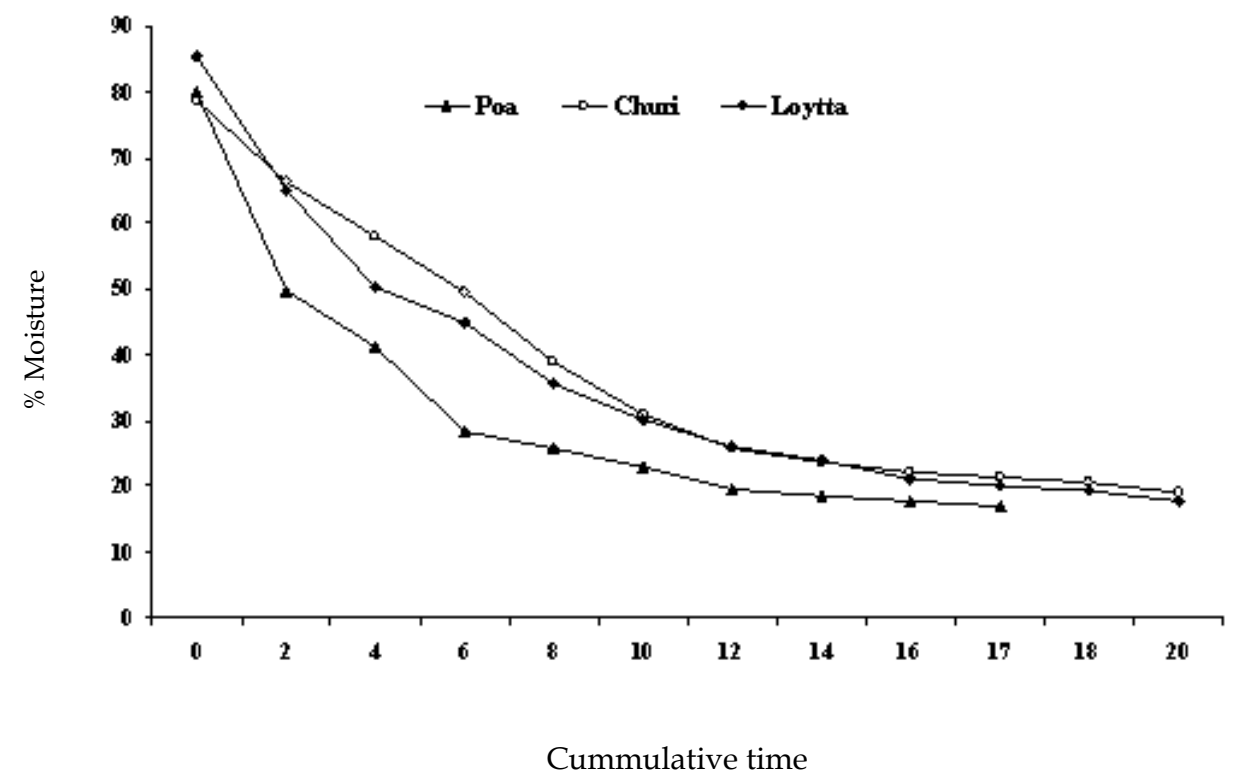

Fig. 6. Changing in moisture content with cummulative time interval during drying in solar tunnel dryer 
From the above discussion it may concluded that drying performances of rotating dryer is faster than that of solar tunnel dryer and high quality of the dried product.

\section{REFERENCES}

Ahmed, M., Bhuiyan, A. D., Alam, A. M. S. and Huda, S. M. S. 1978. Radiation disinfestations studies on sun-dried fish. Indo-Pacific Fishery Commission, Proceedings $18 \mathrm{t}^{\mathrm{th}}$ Session, Manila, Philippines 8-17 March, pp. 310-321.

AOAC (Association of Official Analytical Chemists). 1980. Horwitz, N. (Ed.), Official Methods of Analysis, Association of Official Analytical Chemists, 13'th Ed., Washington DC. 957 pp.

Bala, B. K. and Hossain, M. D. 1998. Experimental investigation of solar drying of fish using tunnel dryer. WREC, Elsevier Science Ltd., 2049-2052.

Bala, B. K. and Mondol, M. R. A. 2001. Experimental investigation of solar drying of fish using tunnel dryer. Drying Technology, 19(2): 1-10.

Doe, P. E., Ahmed, M., Muslemuddin, M. and Sachithananthan, K. 1977. A polythene tent drier for improved sun drying of fish. Food Technology in Australia, 29: 437-441.

Hasan, M. M. 2006. Improvement of food quality of traditional dried small indigenous fish products using rotary dryer and solar tunnel dryer. M. S. Thesis, Department of Fisheries Technology, Bangladesh Agricultural University, Mymensingh, Bangladesh, 126 pp.

Reza, M. S. 2002. Improvement of food quality of traditional marine dried fishery products using solar tunnel drier. M. Sc. Thesis, Department of Fisheries Technology, Bangladesh Agricultural University, Mymensingh, 136pp.

Reza, M. S., Bapary, M. A. J., Azimuddin, K. M. Nurullah, M. and Kamal, M. 2005. Studies on the traditional drying activities of commercially important marine fishes of Bangladesh. Pakistan J. Biol. Sci., 8(9): 1303-1310.

Wood, C. D. 1981. The prevention of losses in cured fish. FAO Fisheries Technical Paper. 219, 87 pp. 